\title{
Simulation of the Relaxation Potential Profile of an ac-dc-ac Test
}

\author{
Kerry N. Allahar, ${ }^{1}$ Michael F. Hurley, ${ }^{1}$ Erik D. Sapper, ${ }^{2}$ and Darryl P. Butt ${ }^{1}$ \\ ${ }^{1}$ Department of Materials Science and Engineering, Boise State University, Boise, ID 83725, USA \\ ${ }^{2}$ Boeing Research \& Technology, P.O. Box 3707, M/C 19-LX, Seattle, WA 98124, USA \\ Correspondence should be addressed to Kerry N. Allahar; kerryallahar@boisestate.edu
}

Received 3 December 2013; Accepted 4 March 2014; Published 3 April 2014

Academic Editor: Ramana M. Pidaparti

Copyright (C) 2014 Kerry N. Allahar et al. This is an open access article distributed under the Creative Commons Attribution License, which permits unrestricted use, distribution, and reproduction in any medium, provided the original work is properly cited.

\begin{abstract}
The relaxation period of the accelerated ac- $\mathrm{dc}$-ac test for coatings is associated with the transient electrochemistry that occurs when the immersed coated system is allowed to return to a stable open-circuit condition after being subjected to a cathodic potential. A mathematical model of the transient electrochemistry that occurs during this relaxation period is presented for coated aluminum. Expressions for the corrosion potential and corrosion current as functions of the local $\mathrm{pH}$ at the metalcoating interface were developed using reported experimental results. These expressions enabled the simulation of the transient electrochemistry under the constraint of balanced anodic and cathodic current densities. Regression of the transient relaxation potential profiles to exponential decay functions provided time-constant characterization of the profiles. Simulated results are presented that demonstrate the influences of the coating's porosity and thickness, the applied dc potential and the metal-coating interface condition on the time-constants associated with the relaxation profile. Interpretation of experimentally reported relaxation potential profiles supported the analysis of the simulated results.
\end{abstract}

\section{Introduction}

Industrial metallic structures are subjected to weathering conditions that promote corrosion and eventual loss in design expectations of structural integrity and aesthetic appeal. Mitigation of corrosion exacerbated by aggressive weathering conditions is primarily achieved through the use of organic coatings with its use being more common than corrosion inhibitors, metallic coatings, and anodic and cathodic protection approaches [1]. Metallic surfaces with organic coatings are isolated from the environment with the coating significantly reducing the transport of water and entrained ionic species between the environment and the covered metal-coating interface. Multilayer coating systems, designed with each layer providing a specific protection, have expected service lifetimes of years under actual weathering conditions. However, increased protection translates into lengthy times for performance characterization, necessitating accelerated testing.
Conventional accelerated testing methods such as salt fog (ASTM B117), Prohesion, and Prohesion/QUV (ASTM D894) were designed to simulate aggressive environments that would promote coating degradation while allowing periodic monitoring. The continual development of organic coatings has resulted in coatings that undergo degradation in months to years, even under conventional accelerated testing conditions. Extension of coating lifetimes increases the time required for ranking coating performance and slows down the iterative process of coating development, selection, and qualification. Nonconventional accelerated test methods that promote failure in considerable less time than the conventional test methods have been presented in literature. Essential to these tests is that the reduction in the time to failure for an organic coating is due to the acceleration of the expected corrosion mechanisms and not the introduction of a new process.

The nonconventional accelerated ac-dc-ac test for coatings introduced by Hollaender et al. involves subjecting a 
coated metal to cycles comprising three steps $[2,3]$ : an ac testing step in which the coating properties are determined using electrochemical impedance spectroscopy (EIS), a dc step in which a cathodic potential is applied for a given time period to promote cathodic reactions at the metal-coating interface, and a relaxation step where the coating is allowed to relax back to an open circuit condition with the relaxation potential profile monitored. The ac-dc-ac test is primarily used to rank coatings by the number of cycles which can be kept small by utilizing a larger and more cathodic dc current to promote degradation at the metal-coating interface [411]. The interpretation of the relaxation potential profile is based on the assumptions that the presence of a slow process involves the exchange of ions between the coating and the electrolyte, while a fast process involves the completion of the electrochemical reactions [8].

The mathematical model of coated aluminum under immersion was developed to provide insight into the processes occurring during the relaxation step. The model specific to aluminum, however, can be used to assist with the interpretation of the relaxation potential associated with coated aluminum alloys that have heterogeneous surfaces. The transient, one-dimensional model uses a finite difference approach to solve the governing equations of ionic transport and electroneutrality with the electrochemical reactions proving the boundary condition at the metal-coating interface. Expressions for the corrosion potential and corrosion current as functions of the local $\mathrm{pH}$ at the metal-coating interface were developed using experimental results from literature [12]. These expressions enabled the simulation of the relaxation potential profile after a dc step has been terminated. Regression of the transient profiles to exponential decay functions provided time constants associated with the profile [11].

Simulated results are presented and analyzed to demonstrate the influences of the coating's void porosity and thickness, the applied dc potential and the metal-coating interface condition on the time-constants associated with the relaxation profile. The analysis yielded trends in the time constants as function of coating porosity which were supported by trends in experimentally reported relaxation profiles.

\section{Mathematical Development}

2.1. Polarization Behavior. Polarization curves describing the behavior of pure aluminium under deaerated conditions were reported by Lee and Pyun for $0.01 \mathrm{M} \mathrm{NaCl}$ solutions where the $\mathrm{pH}$ was fixed at 7, 12, and 13 [12]. The electrode potential values reported by Lee and Pyun [12] were relative to a saturated calomel electrode and as such all potentials reported here are referenced to a saturated calomel electrode. Parametric values associated with a given polarization curve are the corrosion potential $\left(E_{\text {corr }}\right)$, corrosion current density $\left(i_{\text {corr }}\right)$, anodic Tafel slope $\left(\beta_{a}\right)$, and cathodic Tafel slope $\left(\beta_{c}\right)$. These values were evaluated for the polarization reported by Lee and Pyun [12] and are listed in Table 1. The value of $E_{\text {corr }}$ was obtained from the potential value associated with
TABLE 1: Parameter values obtained from the polarization data of $99.99 \% \mathrm{Al}$ in deaerated $0.01 \mathrm{M} \mathrm{NaCl}$ that was reported by Lee and Pyun [12].

\begin{tabular}{lccc}
\hline & $\mathrm{pH} \mathrm{7}$ & $\mathrm{pH} \mathrm{12}$ & $\mathrm{pH} \mathrm{13}$ \\
\hline$E_{\text {corr }}(\mathrm{V})$ & -1.33 & -1.65 & -1.84 \\
$i_{\text {corr }}\left(\mu \mathrm{A} \mathrm{cm}^{-2}\right)$ & 0.020 & 2 & 20 \\
$\beta_{a}\left(\mathrm{mV} \mathrm{decade}^{-1}\right)$ & 73 & 93 & 78 \\
$\beta_{c}\left(\mathrm{mV} \mathrm{decade}^{-1}\right)$ & -43 & -52 & -55 \\
\hline
\end{tabular}

the smallest magnitude of current density. A horizontal line at this potential value separated the anodic and cathodic segments of a given polarization curve. The value of $\beta_{a}$ was associated with the slope of the line tangential to the anodic part of the curve while the $\beta_{c}$ value was associated with the slope of the tangential line for the bottom cathodic part. The two tangential lines were constructed such that their point of intersection coincided with the horizontal line associated with the $E_{\text {corr }}$ value. The $i_{\text {corr }}$ value was the current density associated with this intersection point.

The $E_{\text {corr }}$ values and $\log \left(i_{\text {corr }}\right)$ values are shown as functions of $\mathrm{pH}$ in Figure 1. The regression of a quadratic equation to the three points in a given plot was made and this is superimposed on the plots. The quadratic lines agree well with the experimental data points. The expressions for the $E_{\text {corr }}$ and $\log \left(i_{\text {corr }}\right)$ as functions of $\mathrm{pH}$ were

$$
\begin{aligned}
& E_{\text {corr }}=-0.021 \mathrm{pH}^{2}+0.335 \mathrm{pH}-2.646, \\
& \log \left(i_{\text {corr }}\right)=0.1 \mathrm{pH}^{2}-1.5 \mathrm{pH}-2.099
\end{aligned}
$$

The assumption that $\log \left(i_{\text {corr }}\right)$ is a function of the local $\mathrm{pH}$ is reasonable with an expression similar to (2) used for the anodic dissolution current of mild steel in aqueous solutions at $300^{\circ} \mathrm{C}[13]$. The assumption that the $E_{\text {corr }}$ is a function of the local $\mathrm{pH}$ is also reasonable as Pourbaix diagrams relate the expected thermodynamic corrosion potential as a function of $\mathrm{pH}$.

The parameters listed in Table 1 were used to construct

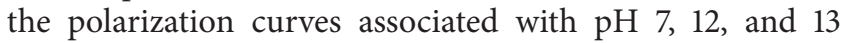
and are shown in Figure 2. Superimposed on this figure is a line labeled (i) that represented the value of $E_{\text {corr }}$ as a function of $i_{\text {corr }}$ for uncoated $\mathrm{Al}$ for a $\mathrm{pH}$ range of 7 to 13 obtained using (1) and (2). This line intersects the locations associated with the $i_{\text {corr }}$ values for a given polarization curve. The consistency between the $E_{\text {corr }}$ and $i_{\text {corr }}$ values obtained from (1) and (2) with the polarization curves supported the use of these equations although they were obtained from a limited number of experimental data points. The polarization behavior of the metal-coating interface at open circuit conditions was assumed to be related to the local $\mathrm{pH}$ at the metal-coating interface, $p_{\text {mci }}$. It was assumed that the relationship between the metal potential, $E_{m}$, at the metalcoating interface at an open-circuit condition and the local $\mathrm{pH}$ is the same for the coated metal as for the uncoated metal with the value of the $E_{m}$ given by

$$
E_{m}=E_{\text {corr }}\left(p_{\text {mci }}\right) \text {, }
$$




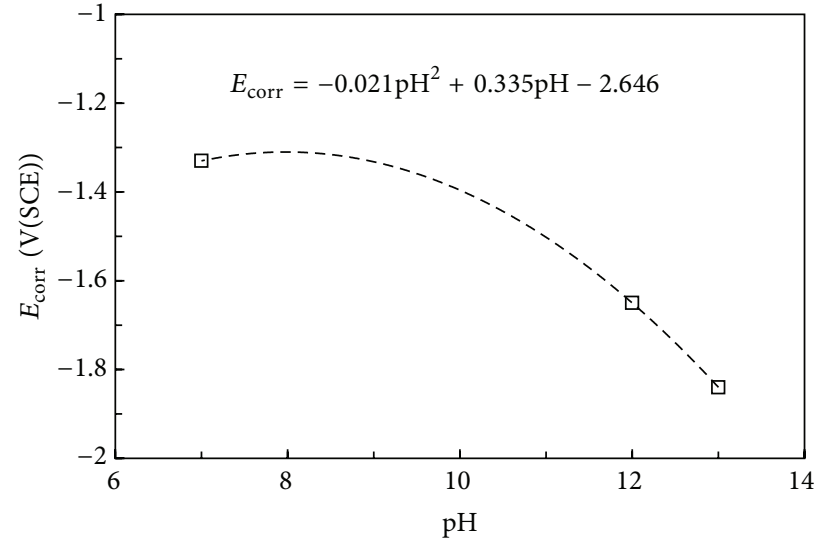

(a)

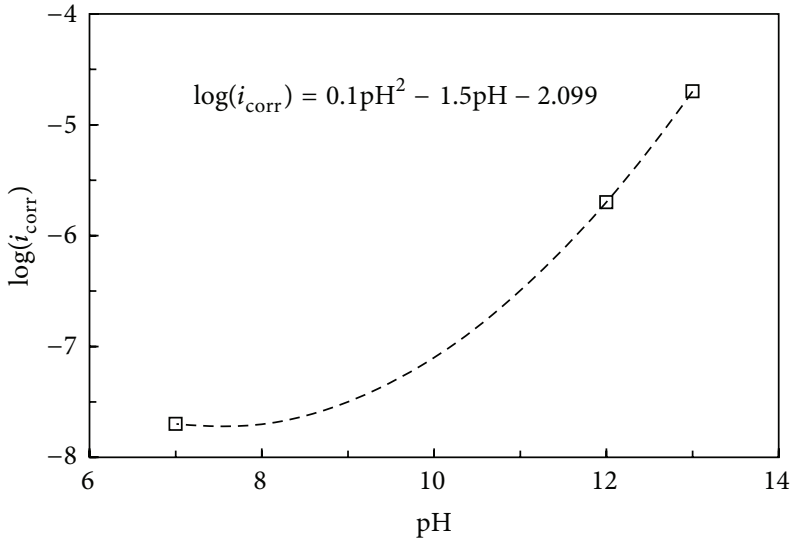

(b)

Figure 1: (a) Corrosion potential and (b) corrosion current density as functions of pH. The experimental data was obtained using the plots reported by Lee and Pyun [12]. Superimposed on the plots are quadratic lines that represent a fit to the data.

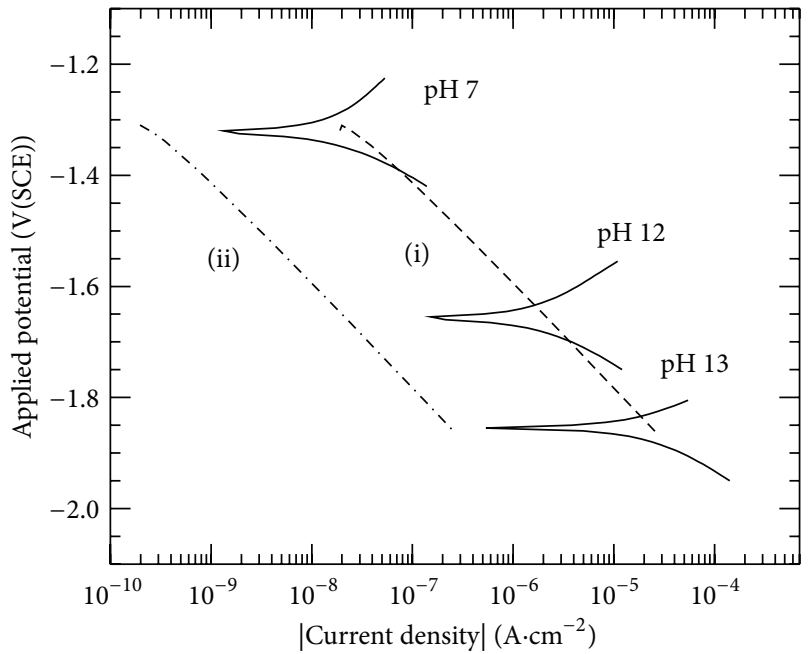

Figure 2: Metal potential as a function of current density for uncoated $\mathrm{Al}$ in a deaerated $0.1 \mathrm{M} \mathrm{NaCl}$ electrolyte. The graphs

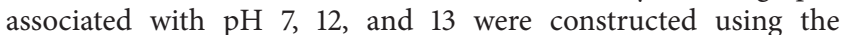
parameters listed in Table 1. The dashed lines represent the metal potential and current density relationships for (i) uncoated $\mathrm{Al}$ and (ii) coated $\mathrm{Al}$ at an open circuit condition for the $\mathrm{pH}$ range of 7 to 13.

where $E_{\text {corr }}$, a function of $p_{\mathrm{mci}}$, is given by (1). This assumption will be addressed after experimental data is obtained and can be viewed as the absence of overvoltages due to the presence of the coating. The current density at the metal coating interface at an open-circuit condition, $i_{m}$, was assumed to be related to the local $\mathrm{pH}$ and a weighting parameter, $\omega$,

$$
i_{m}=\omega i_{\text {corr }}\left(p_{\text {mci }}\right),
$$

where $i_{\text {corr }}$, a function of $p_{\mathrm{mci}}$, is given by (2). The use of a weighting parameter to account for the reduction in the current density at a buried metal-coating interface has been reported [14]. The line labeled (ii) in Figure 2 represented $E_{m}$ as a function of $i_{m}$ for the $\mathrm{pH}$ range of 7 to 13 . This line was constructed using (3) and (4) with the weighting parameter $\omega$ set to 0.01 .

2.2. Governing Equations for Model. There have been numerous mathematical models of the electrochemistry in occluded systems of pits and crevices reported [15-17]; however, there are limited efforts where the electrochemistry for coating systems is explicitly modeled $[14,18]$ and the porosity is addressed. The latter is presented here for a one-dimensional model of the electrochemistry associated with an immersed coated metal in an electrolyte. The development of the governing equations is similar to the crevice and pit models where mass conservation and electroneutrality are the governing equations. The model presented was developed such that the constraint of a net zero current density is maintained during the evolution of the transient electrochemistry. This was done by using the local $\mathrm{pH}$ at a given time to determine the metal potential and current density using (3) and (4). This approach has not been presented before in literature to the best of the author's knowledge and represents a novel strategy at determining the metal potential and current density at an open circuit condition that is not necessarily at steady state.

The domain was divided into an electrolyte domain and a coating domain. Four ionic species were considered, $\mathrm{Na}^{+}$, $\mathrm{Cl}^{-}, \mathrm{OH}^{-}$, and $\mathrm{Al}^{3+}$, together with the solution potential, $\Phi$. The ionic species $\mathrm{H}^{+}$was not included with the $\mathrm{pH}$ values obtained using the $\mathrm{OH}^{-}$ion concentration. This is a reasonable assumption as the $\mathrm{pH}$ values associated with the simulations were greater than or equal to 9 .

The model was developed to simulate the relaxation potential profile after the coated substrate was subjected to a cathodic potential. This would promote the electrochemical production of $\mathrm{OH}^{-}$ions with insignificant production of $\mathrm{Al}^{+3}$ ions. The $\mathrm{Al}^{+3}$ ions exist in hydrated forms as $\mathrm{Al}(\mathrm{OH})^{2+}$, $\mathrm{Al}(\mathrm{OH})_{2}{ }^{+}$, and $\mathrm{Al}(\mathrm{OH})_{4}{ }^{-}$. Inclusion of these minor species through homogeneous reactions would have resulted in a stiff coefficient matrix with convergence problems. The focus of this effort was to develop a model that can simulate lengthy 
periods of time that are similar to those observed during ac-dc-ac testing. Therefore, these minor species were not included in order to obtain simulation periods on the order of hours.

The modeling of the electrolyte electrochemistry was similar to models that have been presented in literature. The governing equation for the concentration of a given species $i$, $c_{i}$, in the electrolyte was the conservation of mass given by

$$
\frac{\partial c_{i}}{\partial t}=-\nabla \cdot N_{i}+R_{i}
$$

where $N_{i}$ is the flux of the specie and $R_{i}$ is the production of a species by homogeneous reactions. There were no homogeneous reactions considered with $R_{i}$ being set to a zero value. In the electrolyte, the flux of a species in the absence of convection is given by the Nernst-Planck expression

$$
N_{i}=-z_{i} c_{i} u_{i} F \nabla \Phi-D_{i} \nabla c_{i}
$$

where $z_{i}$ is the charge number, $u_{i}$ is the mobility, $\Phi$ is the solution potential, $D_{i}$ is the diffusion coefficient for the species, and $F$ is Faraday's constant. A combination of the expression [14]

$$
u_{i}=\frac{D_{i}}{R T}
$$

where $R$ and $T$ are the universal gas constant and temperature, respectively, with (5), (6), and (7) yielded the governing equation for the transport of a species in the electrolyte

$$
\frac{\partial c_{i}}{\partial t}=-\frac{z_{i} c_{i} D_{i} F}{R T} \frac{\partial^{2} \Phi}{\partial x^{2}}-\frac{z_{i} F D_{i}}{R T} \frac{\partial c_{i}}{\partial x} \frac{\partial \Phi}{\partial x}-D_{i} \frac{\partial^{2} c_{i}}{\partial x^{2}}
$$

The governing equation for the solution potential in the electrolyte was the condition of electroneutrality:

$$
\sum_{i} z_{i} c_{i}=0
$$

A similar development can be made such that the governing equation for a species in the coating is

$$
\begin{aligned}
\frac{\partial \varepsilon c_{i, c}}{\partial t}= & -\frac{z_{i} c_{i, c} D_{i} \varepsilon^{1.5} F}{R T} \frac{\partial^{2} \Phi_{c}}{\partial x^{2}}-\frac{z_{i} D_{i} \varepsilon^{1.5} F}{R T} \frac{\partial c_{i, c}}{\partial x} \frac{\partial \Phi_{c}}{\partial x} \\
& -D_{i} \varepsilon^{1.5} \frac{\partial^{2} c_{i, c}}{\partial x^{2}}
\end{aligned}
$$

with the electroneutrality condition as

$$
\sum_{i} z_{i} c_{i, c}=0
$$

In (10) and (11) the concentration of a species in the coating is represented by $c_{i, c}$ and the solution potential as $\Phi_{c}$. The diffusion coefficient of a species in the coating $D_{i, c}$ is assumed to be related to the porosity $\varepsilon$ by the empirically determined relationship [19]:

$$
D_{i, c}=\varepsilon^{1.5} D_{i}
$$

where the porosity is due to void volume in an inert matrix.
2.3. Boundary Conditions. The boundaries for the coating domain were the metal-coating interface and the electrolytecoating interface. The boundary condition at the metalcoating interface was given by expressions relating the flux of a species and the current density at the interface. The condition for the $\mathrm{Al}^{3+}$ species was

$$
-3 c_{\mathrm{Al}^{3+}, c} \frac{D_{\mathrm{Al}^{3+}}}{R T} \varepsilon^{1.5} F \frac{\partial \Phi_{c}}{\partial x}-D_{\mathrm{Al}^{3+}} \varepsilon^{1.5} \frac{\partial c_{\mathrm{Al}^{3+}, c}}{\partial x}=\frac{i_{\mathrm{Al}, m}}{3 F},
$$

and for the $\mathrm{OH}^{-}$species

$$
-c_{\mathrm{OH}^{-}, c} \frac{D_{\mathrm{OH}^{-}}}{R T} \varepsilon^{1.5} F \frac{\partial \Phi_{c}}{\partial x}-D_{\mathrm{OH}^{-}} \varepsilon^{1.5} \frac{\partial c_{\mathrm{OH}^{-}, c}}{\partial x}=\frac{i_{\mathrm{H}_{2}, m}}{F} .
$$

The current density at the metal-coating interface under open circuit conditions, steady-state or transient, for the aluminum dissolution reaction, $i_{\mathrm{Al}, m}$, and for the hydrogen evolution reaction, $i_{\mathrm{H}_{2}, m}$, was given by $i_{m}$. Expressions similar to (13) were used for the metal-coating interface boundary condition for the $\mathrm{Na}^{+}$and $\mathrm{Cl}^{-}$ions except that there was no production of these species by electrochemical reactions. The boundary conditions at the electrolyte-coating interface were the species concentrations and the solution potential of the electrolyte domain at that interface.

The boundaries for the electrolyte domain were the bulk boundary and the electrolyte-coating interface. The boundary conditions at the bulk boundary for the concentration of the species were the bulk concentrations with the solution potential set to a zero value. The boundary condition at the electrolyte-coating interface for a species in the electrolyte domain was the flux at the interface in the coating domain. This was given by

$$
-z_{i} c_{i} \frac{D_{i}}{R T} F \frac{\partial \Phi}{\partial x}-D_{i} \frac{\partial c_{i}}{\partial x}=-z_{i} c_{i, c} \frac{D_{i}}{R T} \varepsilon^{1.5} F \frac{\partial \Phi_{c}}{\partial x}-D_{i} \varepsilon^{1.5} \frac{\partial c_{i, c}}{\partial x},
$$

where the left-hand-side and right-hand-side of the equation were the fluxes in the electrolyte domain and coating domain, respectively.

2.4. Transient State Modeling. The electrolyte and coating domains were discretized into nodes with a common node at the electrolyte-coating interface. The governing equations for the coating domain included a mass-transfer equation for each of the four species, (10), and the electroneutrality equation, (11). The mass-transfer equations at each nonboundary node were discretized using a central finite difference approximation for the spatial derivative and a backward difference approximation for the boundary condition at the metal-coating interface node. These approximations neglected terms of the second order and higher in the spatial derivatives. The first-order temporal derivative was used in terms of the order $\delta t$ and higher neglected. The initial conditions of the coating domain were the steadystate conditions. The discretized equations and the algebraic electroneutrality equation at each node in the coating domain were cast into a matrix form:

$$
K_{c} \cdot C_{c}^{n+1}=R_{c} .
$$


The load vector $R_{c}$ was a function of the current values of $c_{i, c}$ and $\Phi_{c}$ at the nodes in the coating at the time step $n$. The values of $c_{i, c}$ and $\Phi_{c}$ at the nodes for the time step $n+$ 1 were contained in the vector $C_{c}^{n+1}$. The coefficient matrix $K_{c}$ was a function of the nodal $c_{i, c}$ and $\Phi_{c}$ at time step $n+1$. An iterative algorithm utilizing Newton's method was used to solve for $C_{c}^{n+1}$. A convergence criterion of $0.01 \%$ was used.

The governing equations for the electrolyte domain were four mass-transfer equations of the form of (8) and the electroneutrality equation (9). These governing equations in the electrolyte domain were discretized at each node using the central finite difference approximation at nonboundary nodes. A backward difference approximation was used for the expression at the electrolyte-coating boundary. The values of $c_{i, c}$ and $\Phi_{c}$ obtained from solving (16) were used in (15) to calculate the flux of the species at the electrolyte-coating boundary. The bulk boundary was set at the bulk conditions. The discretized equations were cast into a matrix form:

$$
K_{e} \cdot C_{e}^{n+1}=R_{e}
$$

The load vector $R_{e}$ was a function of the current $c_{i}$ and $\Phi$ values at time step $n$ and the coefficient matrix $K_{e}$ was a function of the values $c_{i}$ and $\Phi$ at time step $n+1$. Similar to the coating domain, an iterative algorithm utilizing Newton's method was used to solve for the vector $C_{e}^{n+1}$ which contained the values of $c_{i}$ and $\Phi$ at time step $n+1$. A convergence criterion of $0.01 \%$ was used. The values for $c_{i, c}$ and $\Phi_{c}$ at the coating-electrolyte interface were updated using the solved values for $c_{i}$ and $\Phi$ at time $n+1$ at the electrolyte-coating interface node.

2.5. Steady-State Modeling. The steady-state concentration and solution potential distributions in the electrolyte and coating domains were solved iteratively as well. The governing equations for the mass transfer of a species in the coating were given by

$$
0=-\frac{z_{i} c_{i, c} D_{i} \varepsilon^{1.5} F}{R T} \frac{\partial^{2} \Phi_{c}}{\partial x^{2}}-\frac{z_{i} D_{i} \varepsilon^{1.5} F}{R T} \frac{\partial c_{i, c}}{\partial x} \frac{\partial \Phi_{c}}{\partial x}-D_{i} \varepsilon^{1.5} \frac{\partial^{2} c_{i, c}}{\partial x^{2}},
$$

and in the electrolyte as

$$
0=-\frac{z_{i} c_{i} D_{i} F}{R T} \frac{\partial^{2} \Phi}{\partial x^{2}}-\frac{z_{i} D_{i} F}{R T} \frac{\partial c_{i}}{\partial x} \frac{\partial \Phi}{\partial x}-D_{i} \frac{\partial^{2} c_{i}}{\partial x^{2}}
$$

The governing equations for the electroneutrality condition remained the same as (9) and (11). The conditions at the boundaries also remained the same. The governing equations in the domains were cast into matrix form similar to that described before. The solution method involved the use of bulk boundary conditions initially and the continuity of concentration, solution potential, and flux at the electrolyte-coating interface. The approach is similar to transient approach described before except that there is no timestepping procedure.
2.6. Relaxation Period Modeling. A brief outline of the steps used in calculation procedure is given in Figure 3. The initial conditions in the electrolyte and coating domains were the steady-state conditions calculated using the steadystate model. The relaxation period is initiated when the applied dc potential is switched off such that there is no supply or consumption of current external to the system. This necessitates that any production of current may be consumed within the system; thus, the anodic and cathodic currents are balanced. The current density and metal potential for an open circuit condition at the metal-coating interface are calculated using the local $\mathrm{pH},(4)$ and (3), respectively, and used to calculate the metal-coating interface boundary condition.

The compatibility between the coating and electrolyte domains was achieved by an iterative approach that involved solving (16) and (17). The transient conditions in the coating are calculated using (16) with the condition at the electrolytecoating boundary fixed. The transient conditions in the electrolyte are then solved using (17) with the fluxes in the coating as the electrolyte-coating boundary condition obtained from the solution of (16). Solution of (17) yielded conditions at the electrolyte-coating node which were used to update the boundary node of the coating domain. A convergence criterion of $0.01 \%$ was used for the conditions at electrolytecoating interface. This approach satisfied continuity at the electrolyte-coating interface in terms of concentration and solution potential and flux.

\section{Simulated Results}

The model was used to simulate the transient concentration and solution potential distributions that are resulted during the relaxation period after an applied dc potential is switched off and the system returns to a stable open circuit condition. The initial conditions for the transient model were the steady-state conditions associated with the applied dc potential calculated using the steady-state model. Simulations were performed to demonstrate the influences that the coating thickness, the coating porosity, and the bulk $\mathrm{NaCl}$ concentration had on the electrochemistry during the relaxation period. An effort to understand the influence of the electrochemical reactions at the metal-coating interface is also presented. Two coating thickness values of $0.1 \mathrm{~mm}$ and $0.2 \mathrm{~mm}$ were used. The void porosity values of the coating were $0.02,0.03$, and 0.04 with these values being representative of actual coatings. The bulk $\mathrm{NaCl}$ concentrations were $0.01 \mathrm{M}$ and $0.1 \mathrm{M}$. The bulk concentrations for $\mathrm{Al}^{3+}$ and $\mathrm{OH}^{-}$for all simulations were set at $10^{-15} \mathrm{M}$ and $10^{-5} \mathrm{M}$, respectively, with the bulk $\mathrm{pH}$ being 9. The concentration of $\mathrm{Cl}^{-}$at the bulk was adjusted to satisfy electroneutrality at the bulk boundary. The steady-state electrochemistry for the electrolyte-coating system at an open-circuit condition with a bulk pH of 9 is approximately $-1.34 \mathrm{~V}$ as seen in Figure 1(a).

The diffusion coefficients for the species were $D_{\mathrm{Na}^{+}}=$ $1.334 \times 10^{-5} \mathrm{~cm}^{2} \mathrm{~s}^{-1}, D_{\mathrm{Cl}^{-}}=2.032 \times 10^{-5} \mathrm{~cm}^{2} \mathrm{~s}^{-1}, D_{\mathrm{OH}^{-}}=$ $5.273 \times 10^{-5} \mathrm{~cm}^{2} \mathrm{~s}^{-1}$, and $D_{\mathrm{Al}^{+3}}=0.541 \times 10^{-5} \mathrm{~cm}^{2} \mathrm{~s}^{-1}$ [17]. The values for $\beta_{a}$ and $\beta_{c}$ were set at $80 \mathrm{mV} /$ decade and $-50 \mathrm{mV} / \mathrm{dec}$ de, respectively. The thickness of the electrolyte 


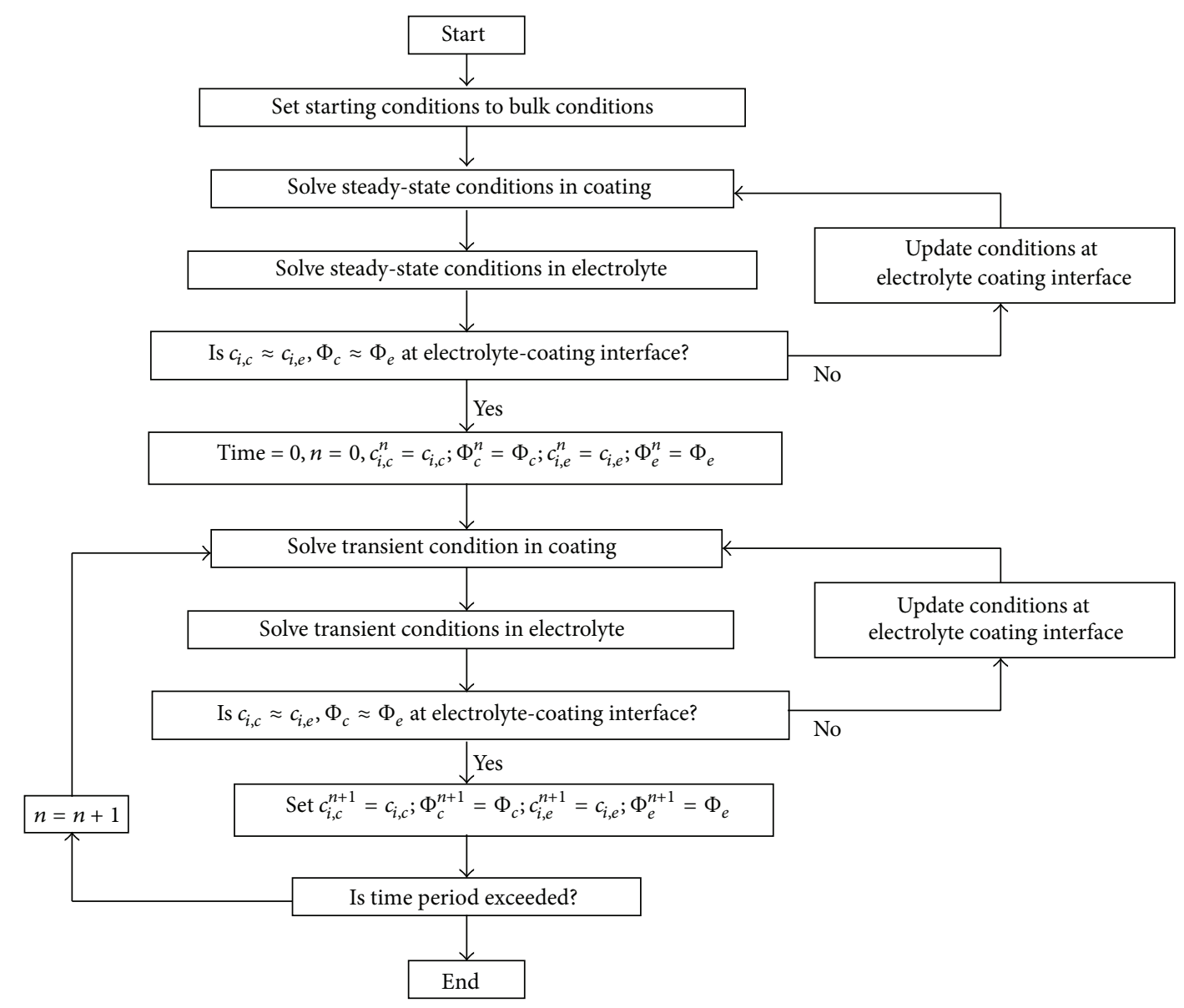

FIGURE 3: Block diagram outlining the solution method used for calculating the steady-state and transient conditions in the electrolyte-coating domain.

solution layer was set at $1 \mathrm{~cm}$. The number of nodes in the electrolyte was 101 while in the coating was 41 for the $0.1 \mathrm{~mm}$ coating and 81 for the $0.2 \mathrm{~mm}$ coating. This yielded values of $\Delta x=0.1 \mathrm{~mm}$ and $\Delta x=1 \mu \mathrm{m}$ for the electrolyte and coating domains, respectively. The time step used was $\Delta t=2 \mathrm{~s}$ and the simulation time was $48000 \mathrm{~s}$ ( $13.3 \mathrm{hrs}$ ). The initial conditions for the transient relaxation period were the steady-state electrochemistry associated with an applied dc potential of $-1.9 \mathrm{~V}$. A dc potential of $-1.6 \mathrm{~V}$ was used to demonstrate the influence of the dc potential on the transient electrochemistry.

3.1. Simulated Solution Potential and Concentrations. The conditions at time $t=0$ were associated with the steady-state condition at the applied cathodic potential of $-1.9 \mathrm{~V}$. At this condition the anodic dissolution is negligible compared to the cathodic hydrogen evolution. The steady-state $\Phi$ distribution at the applied potential of $-1.9 \mathrm{~V}$ is shown in Figure 4 for the $0.1 \mathrm{~mm}$ coating with a value of 0.02 for the porosity. The value of $\Phi$ at the metal-coating interface was $-4.7 \mathrm{mV}$ and this increased to $-1.1 \mathrm{mV}$ across the coating to the electrolytecoating interface and then to the set condition of $0 \mathrm{~V}$ at the bulk boundary. The steady-state open-circuit corrosion potential of $-1.34 \mathrm{~V}$ is associated with a $\mathrm{pH}$ condition of 9 at the metal-coating interface. The steady-state $\Phi$ distribution at $-1.34 \mathrm{~V}$ applied potential and bulk $\mathrm{pH}$ of 9 is also shown in Figure 4. The value of $\Phi$ for this condition is approximately $0 \mathrm{mV}$ with there being no observable change in its value across the coating and the electrolyte. The $-1.34 \mathrm{~V}$ would be associated with a net zero current density as the anodic and cathodic reactions are balanced.

The $\Phi$ distribution 2 min after the applied dc potential of $-1.9 \mathrm{~V}$ is switched off as shown in Figure 4 . The $\Phi$ distribution across the coating decreased from $5.9 \mathrm{mV}$ at the metal-coating interface to $2.1 \mathrm{mV}$ at the electrolyte-coating interface and then to $0 \mathrm{mV}$ at the bulk boundary. This transient distribution was different than that of the $-1.9 \mathrm{~V}$ steady-state condition with the electric fields from the metalcoating interface and bulk boundary being of opposite signs. After 30 min the $\Phi$ distribution had moved much closer to the distribution associated with the $-1.34 \mathrm{~V}$ condition with their being only a drop from $0.2 \mathrm{mV}$ to $0 \mathrm{mV}$ across the coating and no change across the electrolyte. The calculated $\Phi$ distribution indicated the influence of migration transport across the coating during the first 30 minutes.

The steady-state $\mathrm{pH}$ distributions at $-1.9 \mathrm{~V}$ and $-1.34 \mathrm{~V}$ are shown in Figure 5. The $\mathrm{pH}$ distribution at $-1.9 \mathrm{~V}$ 


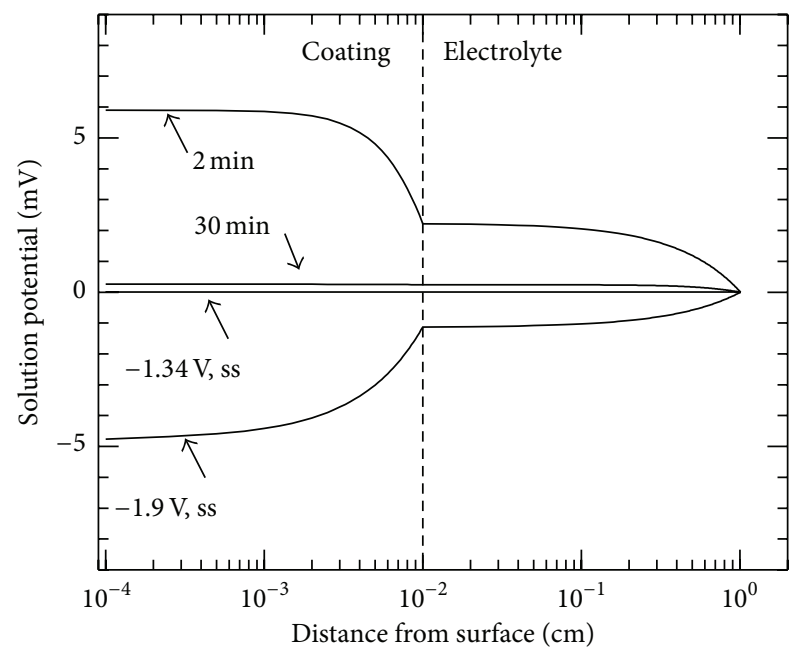

FIGURE 4: Solution potential as a function of distance from the metal surface across the coating and electrolyte for a $0.1 \mathrm{~mm}$ thick, 0.02 porosity coating. Included are the steady state distributions at $-1.34 \mathrm{~V}$ and $-1.9 \mathrm{~V}$ and the transient distributions at $2 \mathrm{~min}$ and $30 \mathrm{~min}$ after the applied potential of $-1.9 \mathrm{~V}$ was switched off.

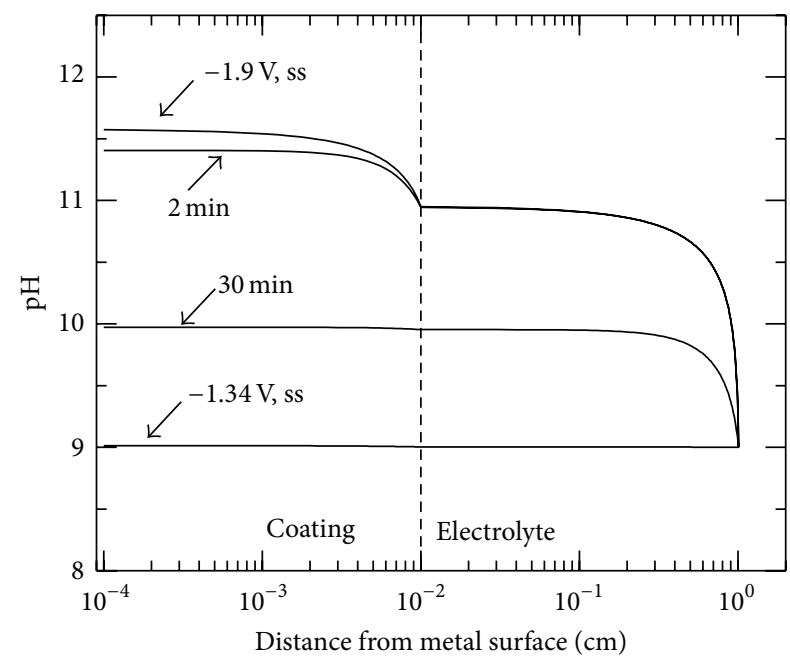

FIGURE 5: $\mathrm{pH}$ as a function of distance from the metal surface across the coating and electrolyte for a $0.1 \mathrm{~mm}, 0.02$ porosity coating. Included are the steady state distributions at $-1.34 \mathrm{~V}$ and $-1.9 \mathrm{~V}$ and the transient distributions at $2 \mathrm{~min}$ and $30 \mathrm{~min}$ after the applied potential of $-1.9 \mathrm{~V}$ was switched off.

decreased from 11.6 at the metal-coating interface to 10.9 at the electrolyte-coating interface to 9 at the bulk boundary. There was little change in the $\mathrm{pH}$ across the coating and electrolyte for the $-1.34 \mathrm{~V}$ condition. The $\mathrm{pH}$ distribution 2 min after the $-1.9 \mathrm{~V}$ applied dc potential was switched off was similar to that of the $-1.9 \mathrm{~V}$ steady-state condition with the $\mathrm{pH}$ value at the metal-coating interface being 11.4 and reducing to 10.9 across the coating. The decrease in $\mathrm{pH}$ at the metal-coating interface was associated with the reduction in the production of $\mathrm{OH}^{-}$ions and the transport of $\mathrm{OH}^{-}$ ions out of the coating. This transport was supported by the electric field across the coating as seen by the $\Phi$ distribution in Figure 4. After 30 minutes, there was little change in $\mathrm{pH}$ across the coating with the $\mathrm{pH}$ being approximately 10 at the electrolyte-coating interface and reducing to approximately 9 at the bulk boundary.

The concentration distributions of the $\mathrm{Na}^{+}$and $\mathrm{Cl}^{-}$ions are shown in Figure 6(a) for the $-1.9 \mathrm{~V}$ and $-1.34 \mathrm{~V}$ steadystate conditions. At the $-1.9 \mathrm{~V}$ condition, there would be a production of the negative $\mathrm{OH}^{-}$ions at the metal-coating interface significantly greater than the production of $\mathrm{Al}^{3+}$ ions. This resulted in the concentration distributions for the positive $\mathrm{Na}^{+}$and $\mathrm{Al}^{3+}$ ions having a larger value at the metal-coating interface and reducing in value across the coating and then across the electrolyte. The presence of these positive species was required to satisfy the electroneutrality condition. The chloride ion distribution increased across the coating and then across the electrolyte. This also facilitated the electroneutrality condition with their being $\mathrm{OH}^{-}$ions being produced at the metal-coating interface. Upon removal of the $-1.9 \mathrm{~V}$ potential, the concentration distributions of $\mathrm{Na}^{+}$and $\mathrm{Cl}^{-}$ions move towards those associated with the $-1.34 \mathrm{~V}$ open circuit condition. The $2 \mathrm{~min}$. distributions of $\mathrm{Na}^{+}$and $\mathrm{Cl}^{-}$ions indicated that $\mathrm{Na}^{+}$ions were transported out of the coating while the $\mathrm{Cl}^{-}$ions were transported into the coating. The electric field across the coating and electrolyte facilitated the migration of $\mathrm{OH}^{-}$ions out of the coating; therefore, the transport of $\mathrm{Na}^{+}$ions out of the coating was driven by diffusion and that of $\mathrm{Cl}^{-}$ions into the coating also by diffusion.

The concentration distributions of the $\mathrm{Al}^{3+}$ ion are shown in Figure $6(\mathrm{~b})$ for the $-1.9 \mathrm{~V}$ and $-1.34 \mathrm{~V}$ steady-state conditions. At the $-1.9 \mathrm{~V}$ condition, there was a production of $\mathrm{Al}^{3+}$ ions at the metal-coating interface which resulted in the concentration distribution being highest at the metal-coating interface and reducing across the coating and the electrolyte. The steady-state distribution at $-1.34 \mathrm{~V}$ was similar to the concentration at the metal coating interface being larger for the more anodic $-1.34 \mathrm{~V}$ as compared to the $-1.9 \mathrm{~V}$. The distribution $2 \mathrm{~min}$ after the applied potential was switched off including a concentration at the metal-coating interface larger than that of the $-1.34 \mathrm{~V}$ steady-state conditions which decreased across the coating and electrolyte. The large concentration at the metal-coating interface was attributed to the influx of $\mathrm{Al}^{3+}$ ions driven by migration. The distribution after 30 min was similarly shaped as the $-1.34 \mathrm{~V}$ steady state condition with the distributions after $30 \mathrm{~min}$ approaching that of the $-1.34 \mathrm{~V}$ condition.

3.2. Simulated Relaxation Potential and Current. The metal potential and current density evolutions are shown in Figure 7 for the $0.1 \mathrm{~mm}$ and $0.2 \mathrm{~mm}$ thick coatings with porosity of 0.02 where the bulk conditions were $0.01 \mathrm{M}$ $\mathrm{NaCl}$, a pH of 9 , and an $\mathrm{Al}$ concentration of $10^{-15} \mathrm{M}$. The simulated results are shown for a period of 11 hours with the reasonable assumption that the metal potential was approximately equal to the steady-state open circuit potential, $-1.34 \mathrm{~V}$, at such time. The metal potential at time $t=0$ was $-1.9 \mathrm{~V}$ with the steady-state electrochemistry in the coating and the electrolyte used as the initial conditions. The $E_{m}$ value 


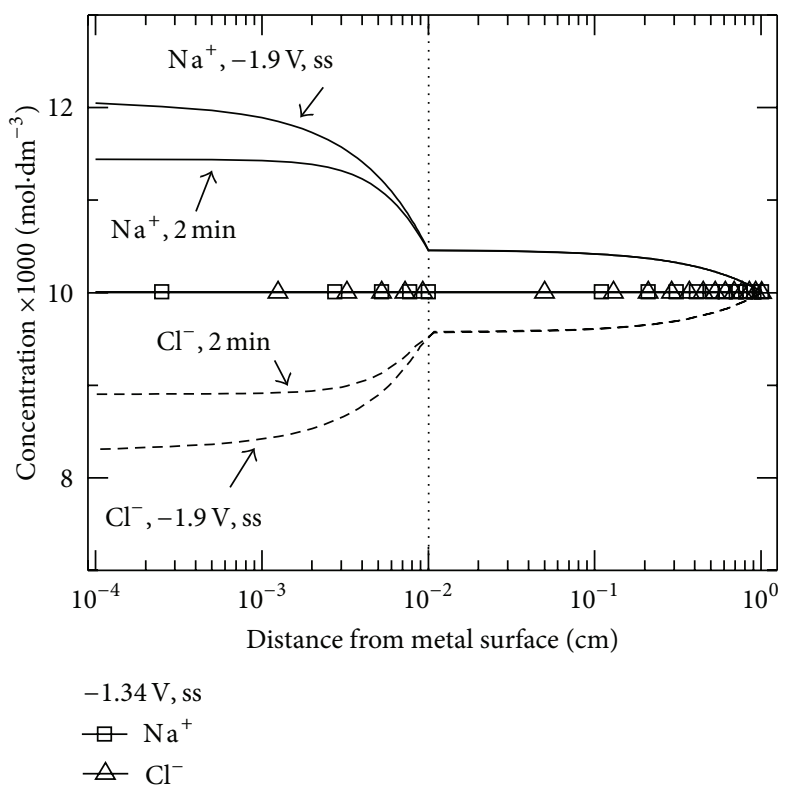

(a)

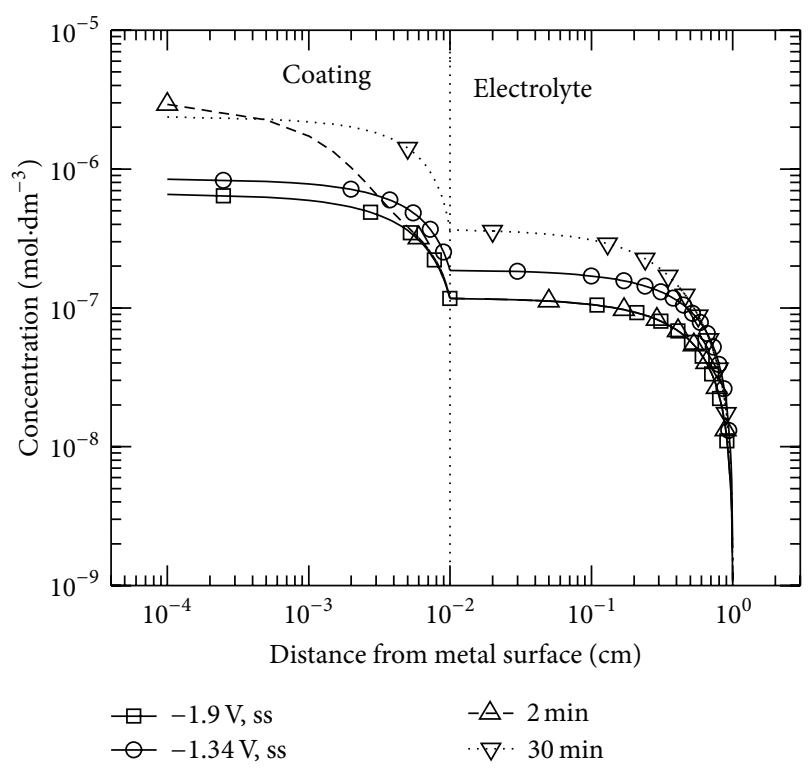

(b)

FIGURE 6: (a) $\mathrm{Na}^{+}$and $\mathrm{Cl}^{-}$ion and (b) $\mathrm{Al}^{3+}$ ion concentrations as functions of distance from the metal surface across the coating and electrolyte for a $0.1 \mathrm{~mm}, 0.02$ porosity coating. Included are the steady state distributions at $-1.34 \mathrm{~V}$ and $-1.9 \mathrm{~V}$ and the transient distributions at 2 min and $30 \mathrm{~min}$ after the applied potential of $-1.9 \mathrm{~V}$ were switched off.

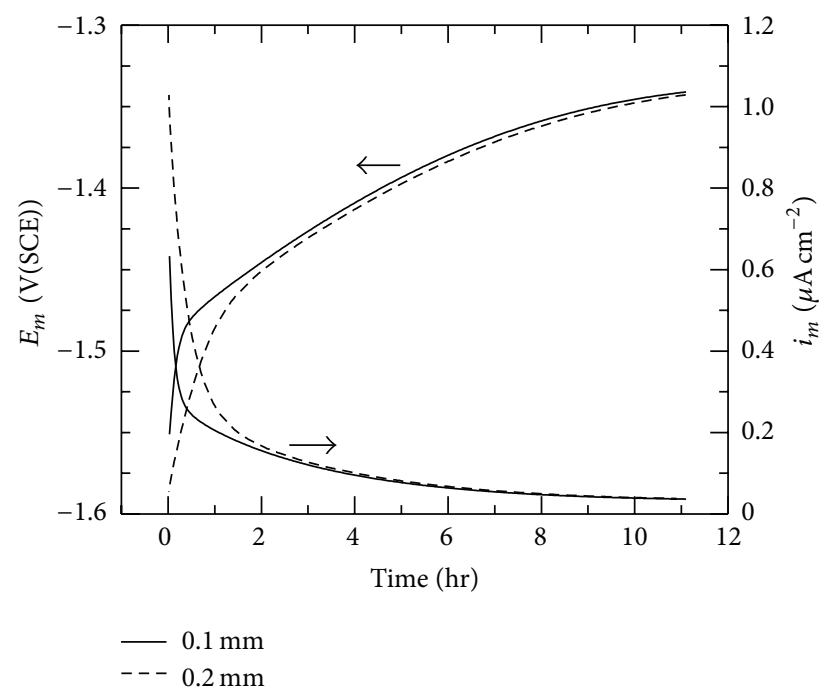

FIGURE 7: Transient metal potential and circuit current density with coating thickness as a parameter for coatings of porosity 0.02 .

after the first $60 \mathrm{~s}$ was $-1.55 \mathrm{~V}$. This increase of $0.35 \mathrm{~V}$ was attributed to the $i R$ drop across the coating and electrolyte. At the $-1.9 \mathrm{~V}$ there was a production of cathodic current by the hydrogen evolution reaction at the metal-coating interface with electrons being supplied to the metal by the applied potential. On switching off the applied dc potential, there would be no more external supply of current with the net current at the metal-coating interface being zero.
The $E_{m}$ value during the relaxation period increased in two observable trends as seen in Figure 7. The evolution of $E_{m}$ for the $0.1 \mathrm{~mm}$ coating during the first $5 \mathrm{~min}$ increased from $-1.55 \mathrm{~V}$ to $-1.49 \mathrm{~V}$ after which it increased to $-1.34 \mathrm{~V}$ during the following 10 hours. During this relaxation period the constraint of a zero net current density is achieved by the cathodic and anodic reactions being balanced. The current density at the metal-coating interface $i_{m}$ that is shown was associated with either the anodic reaction or the modulus of the cathodic reaction. The evolution of $i_{m}$ for the $0.1 \mathrm{~mm}$ coating simulation involved a decrease in value over the first $5 \mathrm{~min}$ followed by a less sharp decrease that had an asymptotic approach to $0.02 \mu \mathrm{Acm}^{2}$ over the remainder of the simulation. It was observed that the initial changes in $i_{m}$ and $E_{m}$ during the first $5 \mathrm{~min}$ were related while the slower changes in $i_{m}$ and $E_{m}$ over the rest of the simulation were related.

The $-1.9 \mathrm{~V}$ applied at $t=0$ was associated with a cathodic reaction and the accompanying production of $\mathrm{OH}^{-}$ions was associated with a negligible anodic reaction. The initial $\mathrm{pH}$ at the metal-coating interface was 11.7 , a $\mathrm{pH}$ greater than the bulk due to the production of $\mathrm{OH}^{-}$ions. Upon removal of the applied potential, the current densities of the cathodic and anodic reactions were balanced and remained like this for $t>0$. This constraint was met as the model was developed such that $E_{m}$ and $i_{m}$ at the metal-coating interface were calculated from the equations that relate the $E_{m}$ and the $i_{m}$ to the local $\mathrm{pH}$. During the relaxation period, the $\mathrm{pH}$ at the metal-coating interface reduced, as shown in Figure 4, as ions are transported by diffusion and migration between the coating and the electrolyte. The change in $\mathrm{pH}$ resulting from 
the evolution of the electrochemistry resulted in the calculated $E_{m}$ and $i_{m}$ evolutions.

The evolution of $E_{m}$ for the $0.2 \mathrm{~mm}$ coating shown in Figure 7 involved an increase from $-1.69 \mathrm{~V}$ to $-1.475 \mathrm{~V}$ over $1 \mathrm{~h}$ while the increase to $-1.34 \mathrm{~V}$ took the remaining simulation time. There was a longer time period for the initial increase associated with the thicker coating. The rate of change of $E_{m}$ was similar for both coatings after the initial increase and the potential was more positive than $-1.45 \mathrm{~V}$. These results indicated processes involved in the initial increase in $E_{m}$ were sensitive to the coating thickness, while the processes involved in the latter increase were not. The evolution of $i_{m}$ for the $0.2 \mathrm{~mm}$ coating simulation had similar trends as the $0.1 \mathrm{~mm}$ coating that involved a sharp decrease in value over the first $1 \mathrm{~h}$ followed by an asymptotic approach to $0.02 \mu \mathrm{Acm}^{2}$ over the remainder of the simulation.

3.3. Characterization of Relaxation Potential Profile. A fast and a slow process can be observed in the relaxation potential evolutions associated with the $0.1 \mathrm{~mm}$ and $0.2 \mathrm{~mm}$ coatings shown in Figure 7. This would be interpreted, according to literature, as attributed to the ending of the electrochemical reactions and the exchange of ions between the coating and the electrolyte, respectively [8]. The evolution of these processes would have associated time constants. A scaling method was presented in literature to calculate these time constants thereby quantitatively characterizing the relaxation potential evolution [11]. This involves scaling the metal potential using the expression

$$
E_{s}=\frac{E_{t}-E_{i}}{E_{\text {end }}-E_{i}}
$$

where $E_{s}$ is the scaled potential, $E_{i}$ is the initial metal potential, and $E_{\text {end }}$ is the potential at the stable condition. The value of $E_{s}$ as a function of time is shown in Figure 8 for the coatings of thicknesses $0.1 \mathrm{~mm}$ and $0.2 \mathrm{~mm}$ whose metal potential evolution is shown in Figure 7. The expression,

$$
E_{s}=A_{1} \exp \left(\frac{-t}{\tau_{1}}\right)+A_{2} \exp \left(\frac{-t}{\tau_{2}}\right)+y
$$

was regressed, fitted, to the scaled relaxation potential with the time constants $\tau_{1}$ and $\tau_{2}$, preexponential factors $A_{1}$ and $A_{2}$, and constant $y$. The values of parameters for the two relaxation potential evolutions shown in Figure 8 are given in Table 2 . The time constants were identified as $\tau_{1}$ and $\tau_{2}$, where $\tau_{2}>\tau_{1}$. The fast process would be associated with $\tau_{1}$ and the slow process with $\tau_{2}$. A larger value for $\tau_{1}$ was associated with the thicker coating while the values for $\tau_{2}$ were similar for both coatings. This result indicated that the fast process was occurring in a shorter time in the $0.1 \mathrm{~mm}$ coating while the slower process was evolving similarly in both coatings. This method of scaling and regression to (21) quantify the relaxation potential evolutions into time constants that can be analyzed and compared across many different virtual coating systems.

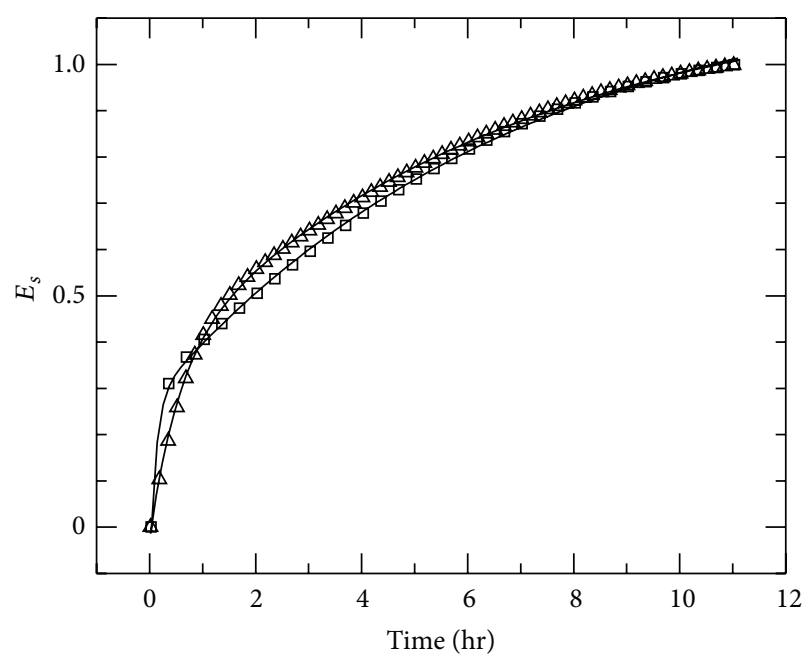

ㅁ $0.1 \mathrm{~mm}$

$\triangle 0.2 \mathrm{~mm}$

FIgURE 8: Evolution of scaled relaxation potential with coating thickness as a parameter. Superposed are the fits of the expression to the simulated evolution.

\section{Influence of Modeling Parameters}

Simulations were performed and the relaxation potential profiles were characterized into contributing time constants to determine the influences of coating thickness, bulk electrolyte concentration, the metal-coating interface condition, and the applied dc potential for coatings of porosity values $0.02,0.03$, and 0.04 .

The values of the time constants for coatings of $0.1 \mathrm{~mm}$ and $0.2 \mathrm{~mm}$ thickness with porosity values of $0.02,0.03$, and 0.04 are shown in Figure 9. The bulk conditions were $0.01 \mathrm{M}$ $\mathrm{NaCl}, \mathrm{pH} 9$, and $10^{-15} \mathrm{M} \mathrm{Al}^{3+}$. The time constant $\tau_{2}$ was insensitive to changes in porosity and coating thickness with an approximate value of $25000 \mathrm{~s}$. The $\tau_{1}$ value was sensitive to the coating porosity with a smaller $\tau_{1}$ value associated with a more porous coating for a given coating thickness. The $\tau_{1}$ value was sensitive to the coating thickness with a larger $\tau_{1}$ value associated with a thicker coating for a given porosity. The $\tau_{1}$ value was associated with the fast process during the relaxation period and this result indicated that this process was influenced by the coating properties of thickness and porosity. The slow process associated with $\tau_{2}$ was not influenced by these coating properties.

The time constant values calculated from the simulations for a coating of $0.1 \mathrm{~mm}$ thickness with porosity values of $0.02,0.03$, and 0.04 under bulk conditions of $0.01 \mathrm{M} \mathrm{NaCl}$ and $0.1 \mathrm{M} \mathrm{NaCl}$ with a bulk $\mathrm{pH}$ of 9 and $\mathrm{Al}^{3+}$ concentration of $10^{-15} \mathrm{M}$ are shown in Figure 10. As noted before, for a given bulk $\mathrm{NaCl}$ concentration, the slow process time constant $\tau_{2}$ was insensitive to changes in porosity while the fast process time constant $\tau_{1}$ was influenced by the coating porosity. Larger values of $\tau_{2}$ and $\tau_{1}$ were associated with a smaller $\mathrm{NaCl}$ bulk concentration for a given porosity. These results indicated that the bulk $\mathrm{NaCl}$ concentration influenced 
TABLE 2: Parameter values for the expression that was regressed to the simulated relaxation potential profile of coatings. The bulk conditions were $0.01 \mathrm{M} \mathrm{NaCl}, \mathrm{pH} 9$, and $10^{-15} \mathrm{M} \mathrm{Al}^{3+}$, and the applied potential was $-1.9 \mathrm{~V}$.

\begin{tabular}{lccccrr}
\hline Coating & $Y$ & $A_{1}$ & $\tau_{1} / \mathrm{s}$ & $A_{2}$ & $\tau_{2} / \mathrm{s}$ \\
\hline $0.1 \mathrm{~mm}$ & $1.227 \pm 0.002$ & $-0.270 \pm 0.005$ & $223 \pm 5$ & $-0.996 \pm 0.001$ & $25900 \pm 100$ & 0.999 \\
$0.2 \mathrm{~mm}$ & $1.198 \pm 0.003$ & $-0.334 \pm 0.003$ & $900 \pm 12$ & $-0.900 \pm 0.002$ & $25500 \pm 160$ & 0.999 \\
\hline
\end{tabular}

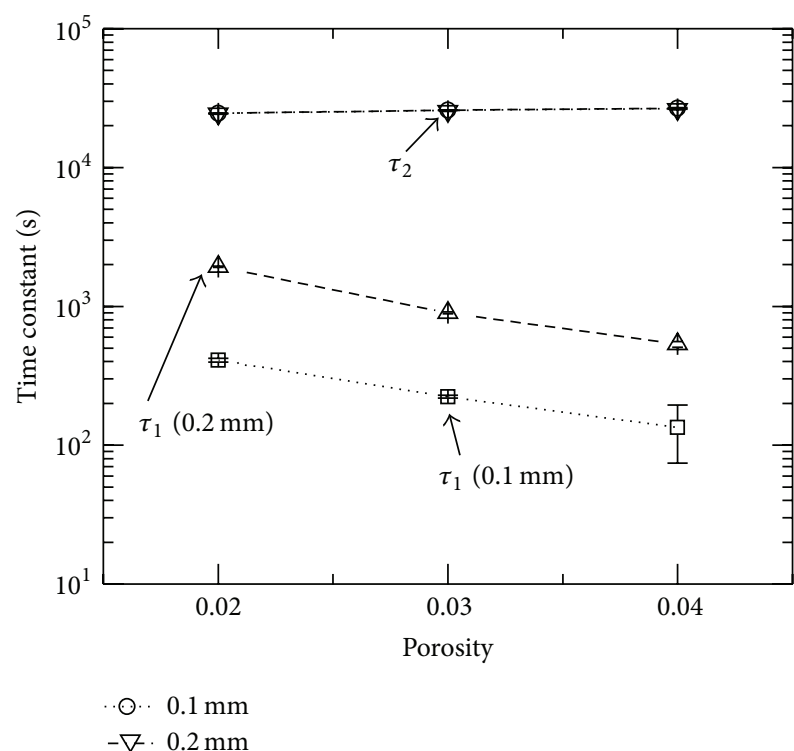

FIGURE 9: Time constants $\tau_{1}$ and $\tau_{2}$ as functions of porosity with the coating thickness as a parameter. The bulk conditions were $0.01 \mathrm{M}$ $\mathrm{NaCl}, \mathrm{pH} 9,10^{-15} \mathrm{M} \mathrm{Al}^{3+}$, and the applied dc potential was $-1.9 \mathrm{~V}$.

both slow and fast processes contributing to the relaxation potential profile.

The influence of the applied cathodic potential at time $t=0$ was determined using the simulation associated with applied dc potentials $-1.9 \mathrm{~V}$ and $-1.6 \mathrm{~V}$ for a $0.1 \mathrm{~mm}$ coating and $0.01 \mathrm{M} \mathrm{NaCl}$ bulk electrolyte. The values for $\tau_{1}$ and $\tau_{2}$ as functions of porosity with the applied dc potential as a parameter are shown in Figure 11. For a given applied dc potential, the slow process associated with $\tau_{2}$ was insensitive to porosity, while the fast process of $\tau_{1}$ was influenced by the coating porosity. The applied dc potential did influence the slow process with a more negative applied dc potential yielding a larger value of $\tau_{2}$ for a given porosity. The applied dc potential was not influential on the fast process associated with $\tau_{1}$. A more negative applied dc potential would result in a larger cathodic current density at the metal-coating interface with their being a larger amount of $\mathrm{OH}^{-}$ions in the coating for the $-1.9 \mathrm{~V}$ dc potential as compared with the $-1.6 \mathrm{~V}$ dc potential. These results indicated that the slow process may be influenced by the applied dc potential due to the greater exchange of ions between the coating and the electrolyte that is required to return to a stable steady-state condition.

The influence of the conditions at the metal-coating interface was investigated by performing simulations where the open circuit current density weighting parameter $\omega$ in (4) was 0.1 and 0.01 . The bulk conditions were $0.01 \mathrm{M} \mathrm{NaCl}, \mathrm{pH} 9$, and $10^{-15} \mathrm{M} \mathrm{Al}^{3+}$ concentration and the coating was $0.1 \mathrm{~mm}$

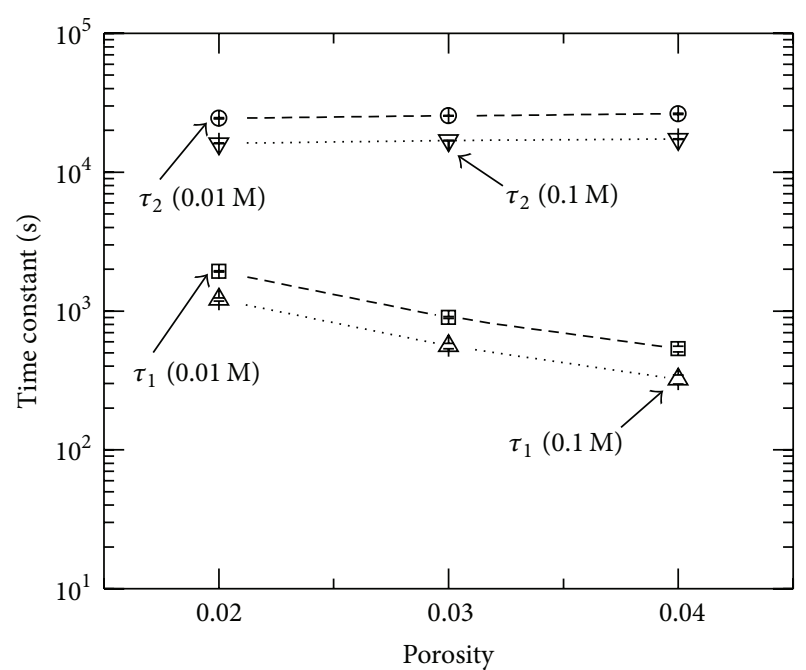

FIGURE 10: Time constants $\tau_{1}$ and $\tau_{2}$ as functions of porosity with the bulk $\mathrm{NaCl}$ concentration as a parameter. The bulk conditions were pH 9 and $10^{-15} \mathrm{M} \mathrm{Al}^{3+}$, the applied dc potential was $-1.9 \mathrm{~V}$, and the coating was $0.2 \mathrm{~mm}$ thick.

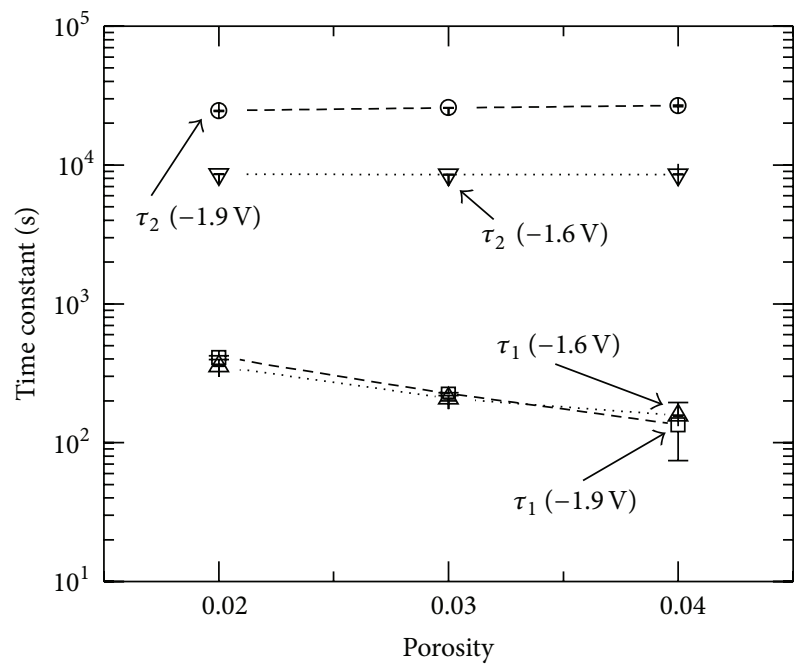

FIGURE 11: Time constants $\tau_{1}$ and $\tau_{2}$ as functions of porosity with applied potential as a parameter. The bulk conditions were $0.01 \mathrm{M}$ $\mathrm{NaCl}, \mathrm{pH}$ 9, and $10^{-15} \mathrm{M} \mathrm{Al}^{3+}$ and the coating was $0.1 \mathrm{~mm}$ thick.

thick. The regressed time constants $\tau_{1}$ and $\tau_{2}$ are shown in Figure 12 for these simulations as functions of porosity and weighting parameter $\omega$. The behavior of $\tau_{1}$ and $\tau_{2}$ for a given weighting parameter was similar to that presented before, with the time constant $\tau_{2}$ insensitive to porosity while $\tau_{1}$ was sensitive to porosity. The fast process associated with the time 


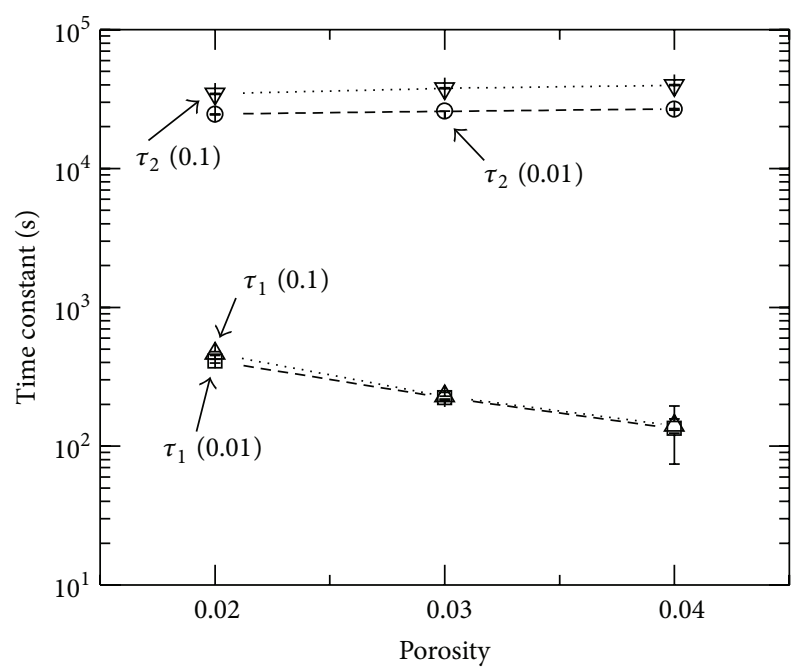

FIGURE 12: Time constants $\tau_{1}$ and $\tau_{2}$ as functions of porosity with the weighting parameter $\omega$ for the current density at the metal-coating interface as a parameter. The bulk conditions were $0.01 \mathrm{M} \mathrm{NaCl}, \mathrm{pH}$ $9,10^{-15} \mathrm{M} \mathrm{Al}^{3+}$ and the coating was $0.1 \mathrm{~mm}$ thick.

constant $\tau_{1}$ was not influenced by the change in the weighting parameter while a larger value of $\tau_{2}$ was associated with a larger cathodic current density at a given porosity. These results further indicated that the slow process was influenced by amount of $\mathrm{OH}^{-}$ions in the coating while the fast process was not.

The fast process associated with the time constant $\tau_{1}$ was on the order of $10^{3} \mathrm{~s}$ and was influenced by the coating thickness and porosity. The slow process associated with $\tau_{2}$ was on the order of $10^{4} \mathrm{~s}$ and was influenced by the quantity of $\mathrm{OH}^{-}$ions in the coating at the initial time. The bulk electrolyte influenced both processes with a larger bulk $\mathrm{NaCl}$ concentration resulting in smaller $\tau_{1}$ and $\tau_{2}$ values. The slow process can be resolved to the exchange of ions between the coating and the electrolyte, a process dominated by diffusion. The fast process was attributed to the degradation of the electric field in the coating, a process dominated by migration. As seen in Figure 4, there was a negligible electric field for the $30 \mathrm{~min}$ solution potential distribution as compared to that of the 2 min distribution. This analysis is consistent with the interpretation used in literature where the slow process is associated with the exchange of ions between the coating and the electrolyte. There is insight gained from the contribution of the coating properties, thickness, and porosity; their influence on the fast process improves our understanding of the overall relaxation process. The electrochemical reactions continue during the relaxation period with anodic and cathodic reactions balanced. The fast process observed is instead related to the ending of the electric field across the coating.

\section{Interpretation of Relaxation Potential Profiles}

Experimental results associated with an ac-dc-ac test were reported by Allahar et al. [11] where the water uptake of the coating was evaluated between each cycle. Also, the applied potential was made more negative after several cycles. The relaxation potential profiles were characterized to yield three time constants similar to the characterization procedure described earlier. The simulated data shown here yielded two time constants and these were similar in magnitude to the experimentally determined time constants of the fastest and slowest processes. There is a missing third time constant from the simulated data which may be unaccounted for in the model. There was a decrease in the experimental time constant of the fastest process during the first 10 cycles where there was also a measured increase in the porosity. During these cycles there was no change in the experimental time constant of the slowest process. These experimental results indicated that the fastest process was sensitive to porosity with a smaller value of time constant for this process associated with a more porous coating and the slowest process unchanged by the coating porosity. This experimental result was similar to the simulated result where the fast process with the $\tau_{1}$ time constant was sensitive to porosity and the slow process, $\tau_{2}$, was insensitive. There was an increase in the slowest experimentally determined time constant when a more negative applied potential was used. This was also observed from the simulated data where a larger value of $\tau_{2}$ was associated with a more negative applied potential.

The results associated with an ac-dc-ac test reported by García and Suay involved a base epoxy with different amounts of an inhibitor [8]. An equivalent circuit was regressed to the EIS data collected during the ac steps and the polarization resistance values were reported. The polarization resistance after 5 cycles of the base epoxy with no inhibitor was four orders of magnitude greater than that of an epoxy/inhibitor coating. This indicated that the current density at the metal/coating interface for the epoxy/inhibitor coating was greater than the epoxy coating by orders of magnitude. The relaxation potential profiles after 5 cycles indicated that a steady state potential was attained after $4000 \mathrm{~s}$ for the epoxy coating and by $10000 \mathrm{~s}$ for the epoxy/inhibitor coating. Based on the analysis presented before, the longer time required for the epoxy/inhibitor coating to attain a steady-state is due to a larger current density at the metal-coating interface which was consistent with the polarization resistance results.

The analysis of the simulated relaxation profiles indicated that two processes contributed to the relaxation period of the coating. The fast process with the smaller time constant was associated with the coating properties while the slow process with the larger time constant was associated with the exchange of ions between the coating and electrolyte. Relaxation potential profiles presented in literature support the analysis of the time constants based on the simulated data.

\section{Conclusions}

A mathematical model was used to simulate the transient electrochemistry associated with the relaxation period of a coating system after being at an applied cathodic potential during an ac-dc-ac test. The constraint that the cathodic and anodic current densities should be balanced was achieved by 
assuming that the metal potential and current density at an open circuit condition were functions of the local $\mathrm{pH}$. The transient change in the distribution of the concentration of the $\mathrm{Na}^{+}, \mathrm{Cl}^{-}$, and $\mathrm{OH}^{-}$ions was monotonic with time with the distributions at $t>0$ approaching that of the open circuit stable condition starting from the distribution at the applied dc potential. The change of the solution potential distribution on the removal of the dc potential was such that the electric field changed, aiding the migration of the negative $\mathrm{OH}^{-}$ species out of the coating and influencing the distribution of the minor $\mathrm{Al}^{3+}$ species distribution.

The relaxation potential profiles were characterized by two time constants calculated by regression. The simulated results demonstrated that the fast process with the smaller time constant, $10^{3} \mathrm{~s}$, was associated with the coating properties of thickness and porosity. The slow process with the larger time constant, $10^{4} \mathrm{~s}$, was associated with the quantity of $\mathrm{OH}^{-}$ions in the coating the initial time. Experimental results from literature supported the interpretation of these fast and slow processes. Future improvements and extensions made to the models presented here will further support improved electrochemical test method interpretation, novel test method development, and increased understanding of corrosion related transport and migration processes.

\section{Conflict of Interests}

The authors declare that there is no conflict of interests regarding the publication of this paper.

\section{Acknowledgments}

This work was supported by the Boeing Research \& Technology, Seattle, WA, USA, and the Boise State University, Boise, ID, USA, and was performed at the Center for Advanced Energy Studies, Idaho Falls, ID, USA.

\section{References}

[1] G. Koch, M. Brongers, N. Thompson, Y. Virmani, and J. Payer, "Corrosion cost and preventive strategies in the United States," Technical Report, CC Technologies Laboratories and NACE International, Dublin, Ohio, USA, 2001.

[2] J. Hollaender, E. Ludwig, and S. Hillebrand, "Assessing protective layers on metal packaging material by electrochemical impedance spectroscopy (EIS)," in Proceedings of the 5th International Tinplate Conference, paper no. 25, pp. 300-315, 1992.

[3] J. Hollaender, "Rapid assessment of food/package interactions by electrochemical impedance spectroscopy (EIS)," Food Additives and Contaminants, vol. 14, no. 6-7, pp. 617-626, 1997.

[4] M. Bethencourt, F. J. Botana, M. J. Cano, R. M. Osuna, and M. Marcos, "Lifetime prediction of waterborne acrylic paints with the AC-DC-AC method," Progress in Organic Coatings, vol. 49, no. 3, pp. 275-281, 2004.

[5] M. Poelman, M.-G. Olivier, N. Gayarre, and J.-P. Petitjean, "Electrochemical study of different ageing tests for the evaluation of a cataphoretic epoxy primer on aluminium," Progress in Organic Coatings, vol. 54, no. 1, pp. 55-62, 2005.
[6] M. T. Rodríguez, J. J. Gracenea, S. J. García, J. J. Saura, and J. J. Suay, "Testing the influence of the plasticizers addition on the anticorrosive properties of an epoxy primer by means of electrochemical techniques," Progress in Organic Coatings, vol. 50, no. 2, pp. 123-131, 2004.

[7] S. J. García and J. Suay, "Anticorrosive properties of an epoxy-Meldrum acid cured system catalyzed by erbium III trifluromethanesulfonate," Progress in Organic Coatings, vol. 57, no. 4, pp. 319-331, 2006.

[8] S. J. García and J. Suay, "Influence on the anticorrosive properties of the use of erbium (III) trifluoromethanesulfonate as initiator in an epoxy powder clearcoat," Corrosion Science, vol. 49, no. 8, pp. 3256-3275, 2007.

[9] G. P. Bierwagen, K. N. Allahar, Q. Su, and V. J. Gelling, "Electrochemically characterizing the ac-dc-ac accelerated test method using embedded electrodes," Corrosion Science, vol. 51, no. 1, pp. 95-101, 2009.

[10] K. Allahar, Q. Su, and G. Bierwagen, "Non-substrate EIS monitoring of organic coatings with embedded electrodes," Progress in Organic Coatings, vol. 67, no. 2, pp. 180-187, 2010.

[11] K. N. Allahar, G. P. Bierwagen, and V. J. Gelling, "Understanding ac-dc-ac accelerated test results," Corrosion Science, vol. 52, no. 4, pp. 1106-1114, 2010.

[12] W. Lee and S. Pyun, "Effects of hydroxide ion addition on anodic dissolution of pure aluminum in chloride ion-containing solution," Electrochimica Acta, vol. 44, no. 23, pp. 4041-4049, 1999.

[13] G. R. Engelhardt, D. D. Macdonald, and P. J. Millett, "Transport processes in steam generator crevices-I. General corrosion model," Corrosion Science, vol. 41, no. 11, pp. 2165-2190, 1999.

[14] K. N. Allahar, M. E. Orazem, and K. Ogle, "Mathematical model for cathodic delamination using a porosity-pH relationship," Corrosion Science, vol. 49, no. 9, pp. 3638-3658, 2007.

[15] K. N. Allahar and M. E. Orazem, "On the extension of CP models to address cathodic protection under a delaminated coating," Corrosion Science, vol. 51, no. 5, pp. 962-970, 2009.

[16] J. Xiao and S. Chaudhuri, "Predictive modeling of localized corrosion: an application to aluminum alloys," Electrochimica Acta, vol. 56, no. 16, pp. 5630-5641, 2011.

[17] O. Guseva, P. Schmutz, T. Suter, and O. von Trzebiatowski, "Modelling of anodic dissolution of pure aluminium in sodium chloride," Electrochimica Acta, vol. 54, no. 19, pp. 4514-4524, 2009.

[18] M. Huang, C. Allely, K. Ogle, and M. E. Orazem, "A mathematical model for cathodic delamination of coated metal including a kinetic pH-porosity relationship," Journal of the Electrochemical Society, vol. 155, no. 5, pp. C279-C292, 2008.

[19] J. S. Newman, Electrochemical Systems, Prentice Hall, Englewood Cliffs, NJ, USA, 2nd edition, 1991. 

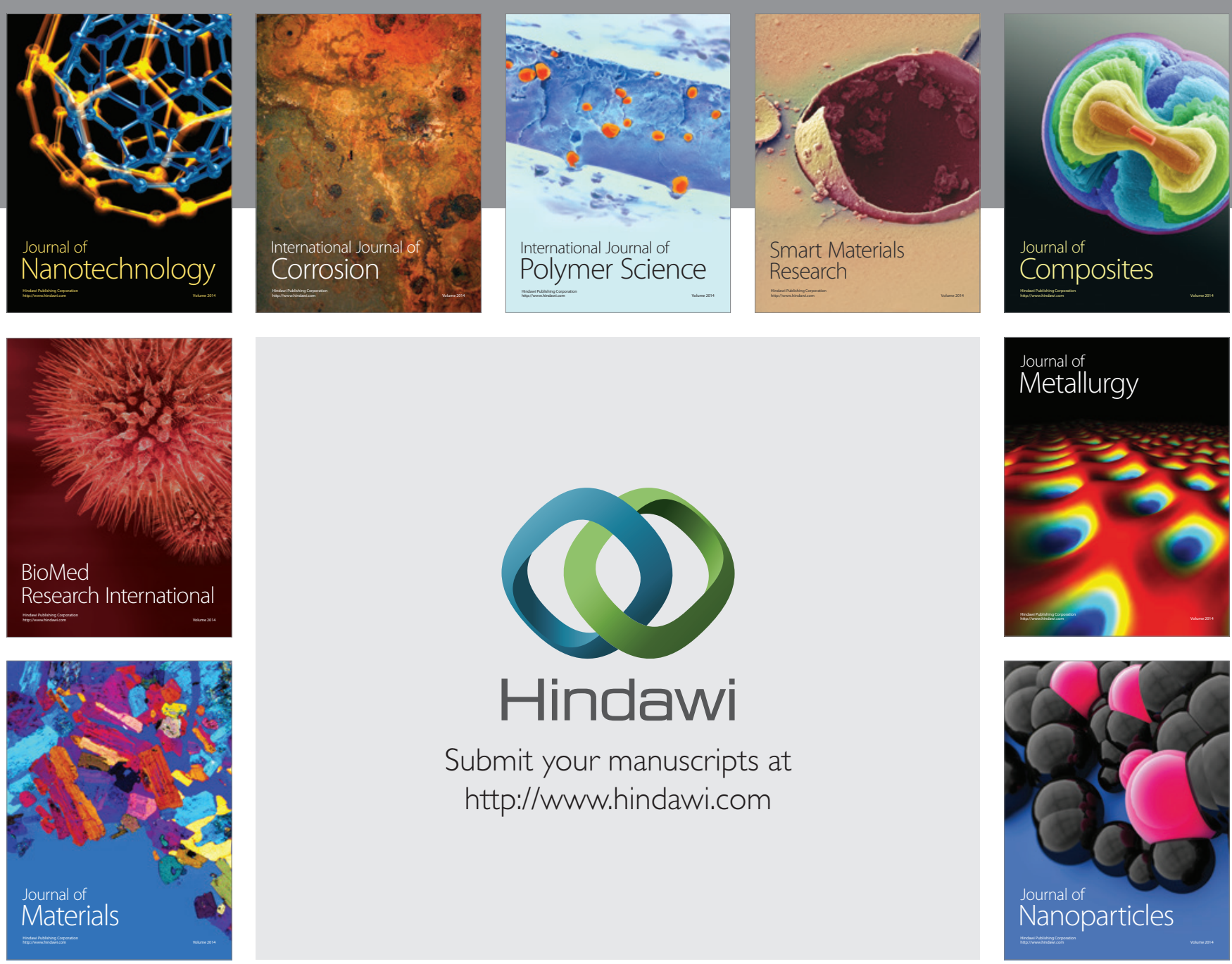

Submit your manuscripts at http://www.hindawi.com
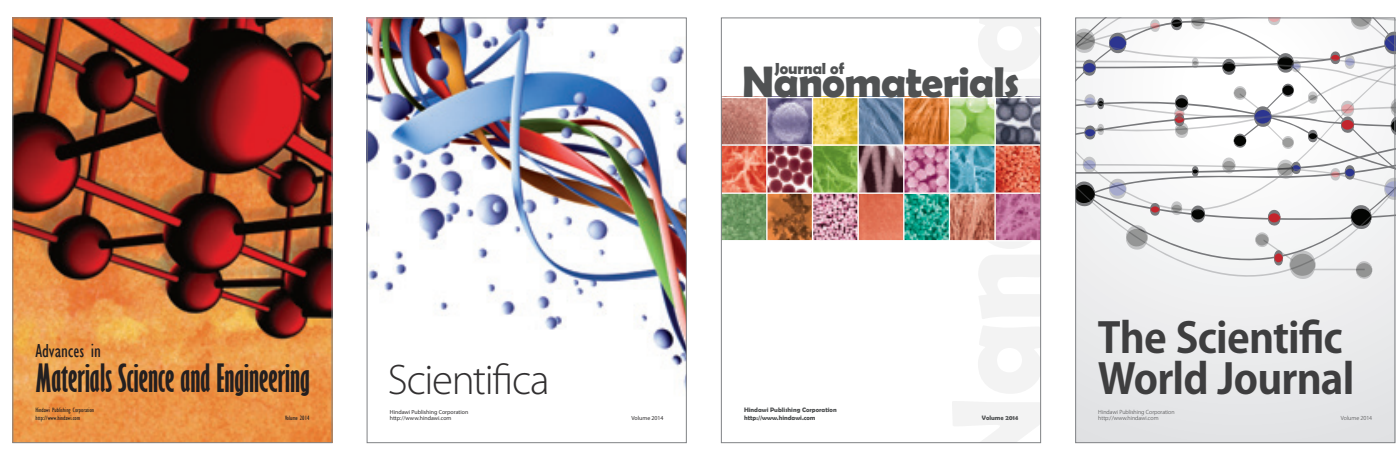

\section{The Scientific World Journal}
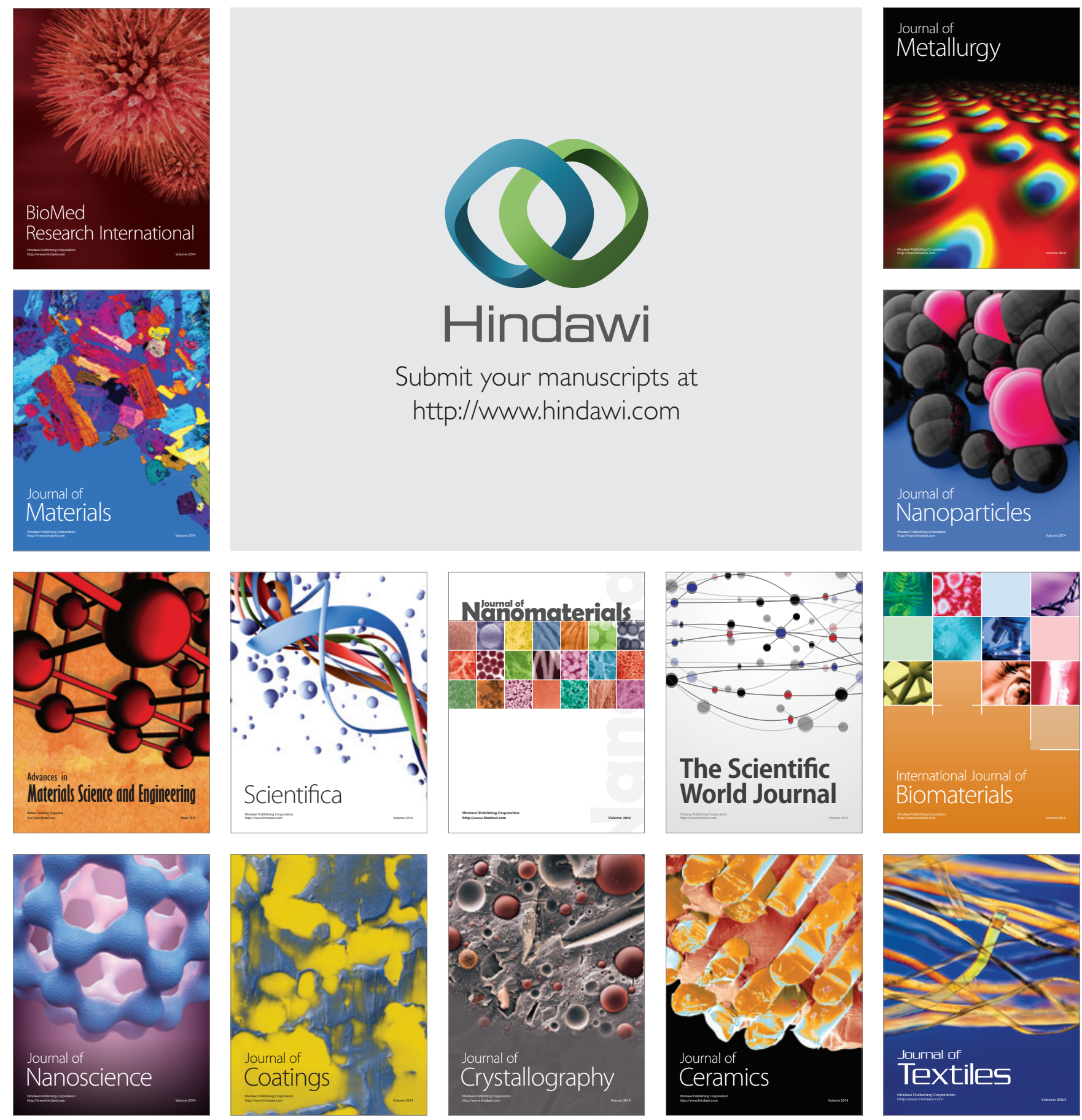